\title{
Obesity is Associated with Worse Outcomes Among Abdominal Trauma Patients Undergoing Laparotomy: A Propensity-Matched Nationwide Cohort Study
}

\author{
Chih-Yuan Fu ${ }^{1,2} \cdot$ Francesco Bajani $^{1} \cdot$ Marissa Bokhari $^{1} \cdot$ Leah C. Tatebe $^{1}$. \\ Frederick Starr $^{1}$ - Thomas Messer $^{1} \cdot$ Matthew Kaminsky $^{1} \cdot$ Andrew Dennis $^{1}$. \\ Victoria Schlanser $^{1} \cdot$ Justin Mis $^{1} \cdot$ Rubinder Toor $^{1} \cdot$ Stathis Poulakidas $^{1} \cdot$ Faran Bokhari $^{1}$
}

Published online: 11 November 2019

(C) Société Internationale de Chirurgie 2019

\begin{abstract}
Introduction Obesity is associated with increased morbidity and mortality in abdominal trauma patients. The characteristics of abdominal trauma patients with poor outcomes related to obesity require evaluation. We hypothesize that obesity is related to increased mortality and length of stay (LOS) among abdominal trauma patients undergoing laparotomies.

Methods Abdominal trauma patients were identified from the National Trauma Data Bank between 2013 and 2015. Patients who received laparotomies were analyzed using propensity score matching (PSM) to evaluate the mortality rate and LOS between obese and non-obese patients. Patients without laparotomies were analyzed as a control group using PSM cohort analysis.

Results A total of 33,798 abdominal trauma patients were evaluated, 10,987 of them received laparotomies. Of these patients, the proportion of obesity in deceased patients was significantly higher when compared to the survivors ( $33.1 \%$ vs. $26.2 \%, p<0.001$ ). Elevation of one $\mathrm{kg} / \mathrm{m}^{2}$ of body mass index independently resulted in $2.5 \%$ increased odds of mortality. After a well-balanced PSM, obese patients undergoing laparotomies had significantly higher mortality rates $[3.7 \%$ vs. $2.4 \%$, standardized difference $(\mathrm{SD})=0.241]$, longer hospital LOS $(11.1$ vs. 9.6 days, $\mathrm{SD}=0.135)$, and longer intensive care unit LOS $(3.5$ vs. 2.3 days, $\mathrm{SD}=0.171)$ than non-obese patients undergoing laparotomies.

Conclusions Obesity is associated with increased mortality in abdominal trauma patients who received laparotomies versus those who did not. Obesity requires a careful evaluation of alternatives to laparotomy in injured patients.
\end{abstract}

The abstract was presented as a poster in the Western Surgical Association 2018 Annual Meeting (November 3-6, 2018 in San Jose del Cabo, Mexico; Presentation number: 70).

Electronic supplementary material The online version of this article (https://doi.org/10.1007/s00268-019-05268-5) contains supplementary material, which is available to authorized users.

Faran Bokhari

fbokhari@cookcountyhhs.org

Chih-Yuan Fu

drfu5564@yahoo.com.tw

Francesco Bajani

francescobajani@hotmail.com

\section{Introduction}

The prevalence of obesity is rising rapidly in the USA (US) and other industrialized nations. Approximately, one-third of the US adult population is obese [1-3]. It is a public health concern associated with numerous medical problems including diabetes, coronary artery disease, hypertension, 
hyperlipidemia, and various types of cancer [4-7]. A high body mass index (BMI) is also associated with postoperative morbidity for patients requiring surgical treatment [8-10].

Previous publications indicate that obesity may increase morbidity and mortality of abdominal trauma patients [11]. Intensive care unit (ICU) admission and mechanical ventilator support are frequently used in the management of abdominal trauma patients and can be markers for poor outcomes in the obese as well [12].

Our study sought to delineate the characteristics of abdominal trauma patients who might have obesity-related adverse outcomes. Although most abdominal trauma patients can be treated non-operatively, some require laparotomies [13, 14]. There is a significant increase in complications, infectious, and surgical, in obese patients following surgical intervention $[8-10,15,16]$.

The National Trauma Data Bank (NTDB) serves as the largest databank for traumatic injuries and outcomes in the USA [17]. In this study, a nationwide analysis was performed using the NTDB to evaluate the role of obesity in abdominal trauma patients who required laparotomies. We hypothesize that obese patients undergoing trauma laparotomy have a higher mortality and longer length of stay (LOS) than non-obese patients. This information will help physicians improve care by modifying protocols for managing obese trauma patients and maintaining a higher index of suspicion for poor outcomes.

\footnotetext{
Thomas Messer

tmesser@cookcountyhhs.org

Matthew Kaminsky

MKaminsky2@cookcountyhhs.org

Andrew Dennis

adennis@cookcountyhhs.org

Victoria Schlanser

vmoscardelli@gmail.com

Justin Mis

Justin.Mis@cookcountyhhs.org

Rubinder Toor

rubindertoor@gmail.com

Stathis Poulakidas

spoulakidas@cookcountyhhs.org

1 Department of Trauma and Burn Surgery, Stroger Hospital of Cook County, Rush University, 1950 West Polk Street, 8th floor, Chicago, IL 60612, USA

2 Department of Trauma and Emergency Surgery, Chang Gung Memorial Hospital, Chang Gung University, Taoyüan, Taiwan
}

Methods

\section{Study design and setting}

A retrospective cohort analysis of abdominal trauma patients in the NTDB was undertaken for the years 2013-2015. The inclusion criteria were patients with blunt or penetrating abdominal trauma (trauma mechanism: blunt or penetrating, origin file: RDS_ECODE and RDS_ECODEDES; ICD-9-CM: 863.xx-869.xx, origin file: RDS_DCODE and RDS_DCODEDES) (Electronic Supplementary Material Table 1). Patients with burns, unknown trauma mechanism, incomplete records, and BMIs less than 15 or greater than 50 were excluded [18]. Patients with abdominal trauma as the dominant injury were the focus of current study. Patients with severe injuries [abbreviate injury scale (AIS) $\geq 3$ ] to other regions, outside of the abdomen, were excluded from the study (Fig. 1) [19].

Data for age, gender (origin file: RDS_DEMO), systolic blood pressure (SBP) in the emergency department (ED), pulse in the ED, respiratory rate (RR) in the ED, Glasgow coma scale (GCS) in the ED (origin file: RDS_ED), blunt or penetrating trauma, transportation time (EMSMINS in origin file: RDS_ED), ED time (EDMINS in origin file: RDS_ED), comorbidities (origin file: RDS_COMORBID), use of transfusion (PCODEs: 99.0-99.09, origin file: RDS_PCODE and RDS_PCODEDES), laparotomies (Electronic Supplementary Material Table 2), injury severity score (ISS), and body mass index (BMI) [body weight $(\mathrm{kg}) /$ body height $\left.(\mathrm{m})^{2}\right]$ were collected and evaluated. Obesity was defined as BMI over $30 \mathrm{~kg} / \mathrm{m}^{2}$ [20]. Mortality, hospital LOS, and ICU LOS (origin file: RDS_DISCHARGE) were designated as outcomes. Patients who were coded as deceased/expired in the column HOSDISP (hospital disposition) were defined as such (origin file: RDS_DISCHARGE). As per the NTDB, comorbidities were defined as alcohol use disorder, bleeding disorder, currently receiving chemotherapy for cancer, congenital anomalies, congestive heart failure, current smoker, chronic renal failure, cerebrovascular accident, diabetes mellitus, disseminated cancer, advanced directive limiting care, functionally dependent health status, history of angina within 30 days, history of myocardial infarction, history of peripheral vascular disease, hypertension requiring medication, prematurity, chronic obstructive pulmonary disease, steroid use, cirrhosis, dementia, major psychiatric illness, drug use disorder, attention deficit disorder/attention deficit hyperactivity disorder, and other [21]. 
Fig. 1 Study population and protocol of current study

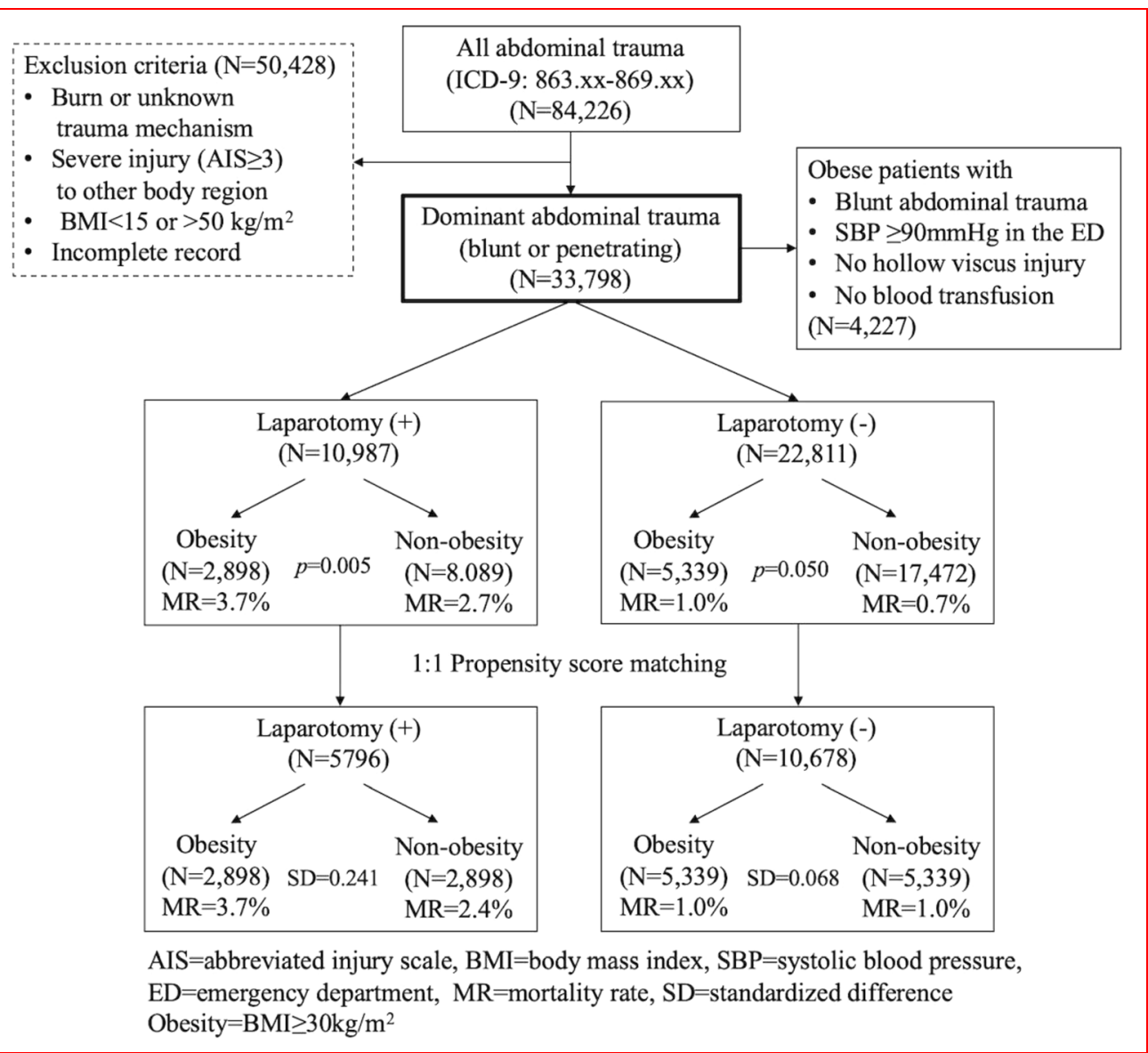

\section{Statistical analysis}

Survivors and non-survivors of abdominal trauma patients who underwent laparotomies were compared (Table 1). Nominal data are presented as a percentage with a 95\% confidence interval (CI) and were compared using Chisquare test, and numerical data are presented as the mean with $95 \% \mathrm{CI}$ and were compared using the Mann-Whitney $U$ test. (ISS was presented as the median and interquartile range.) A value of $p<0.05$ was considered statistically significant. Statistically significant variables in the bivariate analysis were put into a multivariate logistic regression (MLR) model using the "enter method" (gray area of Table 1). CI not including or crossing 1.000 was considered statistically significant. Due to multicollinearity between BMI and obesity, only BMI was included in the regression model. Independent risk factors and the associated odds ratios for mortality of abdominal trauma patients who underwent laparotomies were analyzed accordingly.

We used two analytic approaches to evaluate the effect of obesity on outcomes for abdominal trauma patients who did and did not receive a laparotomy. First, a one-to-one propensity score matching (PSM) methodology was used to minimize selection bias between patients with laparotomies who were obese and non-obese, and constructed pairs of obese patients and non-obese patients with the greedy neighbor approach. A caliper setting of 0.1 was utilized [22]. Standardized differences (SD) were used to confirm a balanced matching result. The matching result was considered balanced when SD was less than 0.1 (Fig. 1, Table 2) [23]. After a well-balanced matching, outcomes between obese and non-obese patients were compared (Table 3). A similar PSM was performed in obese and nonobese patients without laparotomies as a control.

Second, an adjusted MLR model was performed to evaluate the effect of obesity on mortality for patients with laparotomies. Patients without laparotomies were also analyzed using this model as a control group (Table 4). Covariables which may have affected trauma outcomes clinically were considered for PSM and adjusted in the MLR model. These covariables included age, gender (male sex), SBP, pulse, RR, GCS, trauma mechanism (penetrating trauma), transportation time, ED time, comorbidities, use of transfusion, and ISS.

All original files of NTDB were merged and analyzed with $\mathrm{R}$ software, version 3.5.0 of R Core Team ( $\mathrm{R}$ Foundation for Statistical Computing, Vienna, Austria, 2018) and R Studio software, version 1.1.453 of R Studio: 
Table 1 Comparisons of characteristics between non-survivors and survivors and independent risk factors for mortality (multivariate logistic regression) in abdominal trauma patients who received laparotomy $(N=10,987)$

\begin{tabular}{lcccc}
\hline & Bivariate analysis & & \multicolumn{2}{c}{$\begin{array}{c}\text { Multivariate logistic regression } \\
\text { Odds of mortality }\end{array}$} \\
\cline { 2 - 4 } & Non-survivors $(N=323)$ & Survivors $(N=10,664)$ & $p$ value & $1.029(1.021-1.036)$ \\
\hline Age (years) & $44.4(44.1-47.7)$ & $34.2(33.9-34.5)$ & $<0.001^{*}$ & - \\
Male (\%) & $80.8(76.5-85.1)$ & $79.5(79.0-80.6)$ & $0.564^{\dagger}$ & $0.987(0.984-0.990)$ \\
SBP in ED (mmHg) & $92.4(86.7-98.1)$ & $125.5(124.9-126.1)$ & $<0.001^{*}$ & $1.005(1.001-1.009)$ \\
Pulse in ED (/min) & $91.5(86.7-96.3)$ & $93.5(93.0-93.9)$ & $0.029^{*}$ & $0.999(0.983-1.016)$ \\
RR in ED (/min) & $16.7(15.4-17.7)$ & $19.4(19.2-19.5)$ & $<0.001^{*}$ & $0.897(0.860-0.898)$ \\
GCS in ED & $9.0(9.0-10.2)$ & $14.1(14.0-14.1)$ & $<0.001^{*}$ & $1.230(0.938-1.613)$ \\
Penetrating (\%) & $54.5(49.1-59.9)$ & $61.5(60.6-62.4)$ & $0.011^{\dagger}$ & - \\
Transportation time (min) & $172.5(127.7-217.3)$ & $249.0(237.4-260.6)$ & $0.780^{*}$ & $0.999(0.999-1.000)$ \\
ED time (min) & $79.4(64.8-94.0)$ & $114.7(110.6-118.7)$ & $<0.001^{*}$ & - \\
Comorbidity (\%) & $52.3(46.9-57.7)$ & $54.9(54.0-55.8)$ & $0.353^{\dagger}$ & $2.248(1.742-2.901)$ \\
Use of transfusion $(\%)$ & $61.9(56.6-67.2)$ & $24.0(23.2-24.8)$ & $<0.001^{\dagger}$ & $1.086(1.070-1.102)$ \\
ISS & $16(15)$ & $9(9)$ & $<0.001^{*}$ & $1.025(1.005-1.045)$ \\
BMI & $28.4(27.7-29.2)$ & $26.9(26.8-27.1)$ & $<0.001^{*}$ & -
\end{tabular}

Numerical data: mean (95\% CI: lower-upper) (ISS was presented as the median and interquartile range)

Nominal data: percentage (95\% CI: lower-upper)

*Mann-Whitney $U$ test, ${ }^{\dagger}$ Chi-square test, ${ }^{*}$ Multivariate logistic regression (CI not including or crossing 1.000 was considered statistically significant)

$S B P$ systolic blood pressure, $E D$ emergency department, $R R$ respiratory rate, $G C S$ Glasgow coma scale, $I S S$ injury severity score, $B M I$ body mass index, $C I$ confidence interval

Integrated Development for R (R Studio, Inc., Boston, Massachusetts, 2016) [24].

\section{Results}

\section{Characteristics of study subjects}

During the 3-year study period, there were 84,226 abdominal trauma patients (ICD-9: 863.xx-869.xx) in the NTDB. A total of 33,798 patients (Blunt trauma: $75.4 \%$, $N=25,473$; penetrating trauma: $24.6 \%, N=8325)$ were studied with a mean BMI of 26.5. 10,987 patients (32.5\%) received laparotomies (Fig. 1). In patients who underwent laparotomies, non-survivors had a significantly higher BMI (28.4 vs. 26.9, $p<0.001$ ), higher proportion of obesity (33.1\% vs. $26.2 \%, p=0.005$ ). The MLR analysis showed that BMI serves as an independent factor of mortality after adjusting for age, SBP, pulse, RR, GCS, trauma mechanism (penetrating trauma), ED time, use of transfusion, and ISS. Each unit increase in BMI increases the odds of mortality by $2.5 \%$ (odds ratio $=1.025,95 \%$ CI: 1.005-1.045) (Table 1).
Effects of obesity on outcomes in patients who received laparotomies or not were evaluated using PSM and MLR chorot analysis.

The relationship between mortality and BMI in patients who received laparotomies or not is depicted in Fig. 2. A comparison of slopes between these two groups $\left[R^{2}\right.$ of laparotomy $(+)=0.9144, R^{2}$ of laparotomy $(-)=0.8383$ ] demonstrates that the mortality significantly increased as BMI increased among patients receiving a laparotomy [estimated marginal means of laparotomy (+): 2.953 (2.335-3.570), estimated marginal means of laparotomy (-): 1.984 (1.366-2.601), $p<0.001$, analysis of covariance (ANCOVA)].

PSM yielded well-balanced cohorts of 5796 patients with laparotomies from 10,987 patients (2898 obese patients and 2898 non-obese patients) and 10,678 patients without laparotomy from 22,811 patients (5339 obese patients and 5339 non-obese patients) (Table 2). In patients who received laparotomies, the obese had a higher mortality rate $(3.7 \%$ vs. $2.4 \%, \mathrm{SD}=0.241)$, longer hospital LOS (11.1 vs. 9.6 days, $\mathrm{SD}=0.135$ ), and longer ICU LOS (3.5 vs. 2.3 days, $\mathrm{SD}=0.171$ ) than the non-obese after matching. However, there was no significant difference in mortality rate, hospital LOS, or ICU LOS between the 
Table 2 Characteristics of patients who received laparotomies or not

\begin{tabular}{|c|c|c|c|c|c|c|}
\hline \multirow{2}{*}{$\begin{array}{l}\text { Laparotomy }(+) \\
(N=10,987)\end{array}$} & \multicolumn{3}{|c|}{ Pre-propensity matching } & \multicolumn{3}{|c|}{ Post-propensity matching } \\
\hline & $\begin{array}{l}\text { Obese patients } \\
(N=2898)\end{array}$ & $\begin{array}{l}\text { Non-obese patients } \\
(N=8089)\end{array}$ & SD* & $\begin{array}{l}\text { Obese patients } \\
(N=2898)\end{array}$ & $\begin{array}{l}\text { Non-obese patients } \\
(N=2898)\end{array}$ & SD \\
\hline Age (years) & $38.9(38.3-39.5)$ & $32.9(32.5-33.3)$ & 0.353 & $38.9(38.3-39.5)$ & $37.8(37.2-38.5)$ & 0.064 \\
\hline Male $(\%)$ & $79.0(77.5-80.5)$ & $79.7(78.8-80.6)$ & 0.027 & $79.0(77.5-80.5)$ & $80.2(78.7-81.7)$ & 0.041 \\
\hline $\mathrm{SBP}$ in $\mathrm{ED}(\mathrm{mmHg})$ & $127.1(125.9-128.3)$ & $123.6(122.9-124.3)$ & 0.110 & $127.1(125.9-128.3)$ & $127.5(126.5-128.6)$ & 0.015 \\
\hline Pulse in ED (/min) & $95.1(94.3-96.0)$ & $92.8(92.3-93.4)$ & 0.093 & $95.1(94.3-96.0)$ & $95.5(94.7-96.3)$ & 0.017 \\
\hline $\mathrm{RR}$ in $\mathrm{ED}$ (min) & $19.4(19.2-19.7)$ & $19.2(19.1-19.4)$ & 0.031 & $19.4(19.2-19.7)$ & $19.3(19.1-19.6)$ & 0.013 \\
\hline GCS in ED & $13.9(13.8-14.0)$ & $14.0(13.9-14.0)$ & 0.009 & $13.9(13.8-14.0)$ & $14.0(13.8-14.1)$ & 0.010 \\
\hline Penetrating (\%) & $65.9(64.2-67.6)$ & $59.6(58.5-60.7)$ & 0.151 & $65.9(64.2-67.6)$ & $66.4(64.7-68.1)$ & 0.012 \\
\hline $\begin{array}{l}\text { Transportation time } \\
\text { (min) }\end{array}$ & $241.7(221.2-262.2)$ & $248.6(235.0-262.1)$ & 0.011 & $241.7(221.2-262.2)$ & $246.7(223.8-269.6)$ & 0.008 \\
\hline ED time (min) & $107.8(100.8-114.8)$ & $115.7(111.0-120.5)$ & 0.038 & $107.8(100.8-114.8)$ & $104.0(97.5-110.4)$ & 0.021 \\
\hline Comorbidity (\%) & $62.9(61.1-64.7)$ & $52.0(50.9-53.1)$ & 0.247 & $62.9(61.1-64.7)$ & $62.8(61.0-64.6)$ & 0.001 \\
\hline Use of transfusion (\%) & $27.3(25.7-28.9)$ & $24.4(23.5-25.3)$ & 0.082 & $27.3(25.7-28.9)$ & $27.8(26.2-29.4)$ & 0.015 \\
\hline ISS & $9(9)$ & $9(9)$ & 0.042 & $9(9)$ & $9(9)$ & 0.002 \\
\hline \multirow{2}{*}{$\begin{array}{l}\text { Laparotomy }(-) \\
(N=22,811)\end{array}$} & \multicolumn{3}{|c|}{ Pre-propensity matching } & \multicolumn{3}{|c|}{ Post-propensity matching } \\
\hline & $\begin{array}{l}\text { Obese patients } \\
(N=5339)\end{array}$ & $\begin{array}{l}\text { Non-obese patients } \\
(N=17,472)\end{array}$ & SD & $\begin{array}{l}\text { Obese patients } \\
(N=5339)\end{array}$ & $\begin{array}{l}\text { Non-obese patients } \\
(N=5339)\end{array}$ & SD \\
\hline Age (years) & $44.1(43.5-44.7)$ & $31.1(32.7-33.5)$ & 0.432 & $44.1(43.5-44.7)$ & $42.8(42.2-43.4)$ & \\
\hline Male (\%) & $64.1(62.8-65.4)$ & $66.3(65.6-67.0)$ & 0.052 & $64.1(62.8-65.4)$ & $65.4(64.1-66.7)$ & 0.031 \\
\hline SBP in ED (mmHg) & $132.6(131.8-133.4)$ & $127.0(126.6-127.4)$ & 0.199 & $132.6(131.8-133.4)$ & $131.7(131.0-132.4)$ & 0.030 \\
\hline Pulse in ED (/min) & $88.9(89.0-90.1)$ & $88.1(87.8-88.5)$ & 0.064 & $88.9(89.0-90.1)$ & $89.4(88.9-90.0)$ & 0.005 \\
\hline $\mathrm{RR}$ in $\mathrm{ED}(\min )$ & 18.5 (18.3-18.6) & $18.5(18.4-18.6)$ & 0.008 & $18.5(18.3-18.6)$ & $18.3(18.1-18.4)$ & 0.037 \\
\hline GCS in ED & $14.1(14.0-14.2)$ & $14.1(14.1-14.2)$ & 0.003 & $14.1(14.0-14.2)$ & $14.2(14.1-14.3)$ & 0.034 \\
\hline Penetrating (\%) & $7.2(6.5-7.9)$ & $6.9(6.3-7.3)$ & 0.020 & $7.2(6.5-7.9)$ & $8.3(7.6-9.0)$ & 0.088 \\
\hline $\begin{array}{l}\text { Transportation time } \\
\text { (min) }\end{array}$ & $315.8(295.5-336.2)$ & $302.4(291.7-313.1)$ & 0.018 & $315.8(295.5-336.2)$ & $308.9(289.7-328.1)$ & 0.009 \\
\hline ED time $(\min )$ & $309.2(299.7-318.6)$ & $287.2(282.6-291.8)$ & 0.068 & $309.2(299.7-318.6)$ & $293.7(285.4-302.1)$ & 0.046 \\
\hline Comorbidity (\%) & $64.3(63.0-65.6)$ & $46.2(45.5-46.9)$ & 0.409 & $64.3(63.0-65.6)$ & $64.5(63.2-65.8)$ & 0.005 \\
\hline Use of transfusion (\%) & $10.4(9.6-11.2)$ & $7.9(7.5-8.3)$ & 0.168 & $10.4(9.6-11.2)$ & $10.7(9.9-11.5)$ & 0.015 \\
\hline ISS & $9(6)$ & $9(7)$ & 0.058 & $9(6)$ & $9(6)$ & 0.021 \\
\hline
\end{tabular}

Both pre-propensity matching and post-propensity matching between obese patients and non-obese patients are revealed

Numerical data: mean (95\% CI: lower-upper) (ISS was presented as the median and interquartile range)

Nominal data: percentage (95\% CI: lower-upper)

$* \mathrm{SD}=$ standardized difference $(\mathrm{SD} \geq 0.1$ represent significant differences in covariables between groups)

$S B P$ systolic blood pressure, $R R$ respiratory rate, GCS Glasgow coma scale, ED emergency department, ISS injury severity score

obese and non-obese in patients who did not receive laparotomy after matching (Table 3).

In addition to PSM, a MLR analysis showed that in 10,987 patients who received laparotomies, obesity serves as an independent factor to mortality (odds ratio: 1.317, 95\% CI: $1.013-1.712, p=0.040)$ after adjusting for age, gender (male), SBP, pulse, RR, GCS, trauma mechanism (penetrating trauma), transportation time, ED time, comorbidity, use of transfusion, and ISS (Table 4). A similar adjusted regression model was also performed in patients who did not receive a laparotomy $(N=22,811)$ as a control group. Obesity did not affect mortality significantly in patients who did not undergo a laparotomy (Table 4). 
Table 3 Comparisons of outcomes between obese and non-obese patients after propensity score matching

\begin{tabular}{lllr}
\hline & \multicolumn{2}{l}{ Laparotomy $(+)(N=5796)$} & \\
\cline { 2 - 4 } & Obese patients $(N=2898)$ & Non-obese patients $(N=2898)$ & SD* \\
\hline Hospital LOS (day) & $11.1(10.6-11.6)$ & $9.6(9.3-9.9)$ & 0.135 \\
ICU LOS (day) & $3.5(3.2-3.8)$ & $2.3(2.1-2.5)$ & 0.171 \\
Mortality (\%) & $3.7(3.0-4.4)$ & $2.4(1.8-3.0)$ & 0.241 \\
\hline & Laparotomy $(-)(N=10,678)$ & Non-obese patients $(N=5339)$ \\
\cline { 2 - 4 } & Obese patients $(N=5339)$ & $4.7(4.5-4.8)$ & 0.031 \\
\hline Hospital LOS (day) & $4.9(4.7-5.0)$ & $0.7(0.7-0.8)$ & 0.003 \\
ICU LOS (day) & $0.8(0.7-0.8)$ & $1.1(0.8-1.4)$ & 0.068 \\
Mortality (\%) & $1.0(0.7-1.3)$ & & \\
\hline
\end{tabular}

Both patients who received laparotomies or not are revealed

Numerical data: mean (95\% CI: lower-upper)

Nominal data: percentage ( $95 \%$ CI: lower-upper)

$* \mathrm{SD}=$ standardized difference ( $\mathrm{SD} \geq 0.1$ represent significant differences in covariables between groups)

$L O S$ length of stay, ICU intensive care unit

\section{Discussion}

Obesity (BMI $\geq 30 \mathrm{~kg} / \mathrm{m}^{2}$ ) is associated with numerous morbidities, and appropriate management of obese trauma patients is increasingly essential due to its increasing prevalence $[11,12,25]$. Our current study shows that among abdominal trauma patients, increased BMI is an independent risk factor for mortality.

Complications of abdominal surgical incisions may include hemorrhage, infection, or wound dehiscence [26]. Patients undergoing a laparotomy may suffer a pulmonary embolism, deep vein thrombosis, secondary pneumonia, urinary retention, or a reaction to anesthesia [27, 28]. Among patients requiring surgical intervention, obesity is a significant risk factor for surgical wound infections, increased surgical blood loss, and an increased operative time $[8-10,15,16]$. Surgical complications as well as mortality may be increased in obese patients. Therefore, the deleterious role of obesity seems magnified in patients subjected to surgical stress. In obese trauma patients who receive operations, several complications are reported including pneumothorax or hemothorax related to central catheter placement, surgical site infection, surgical wound dehiscence, failure of surgical anastomoses, and increased ventilator days. It is reasonable to assume that more obese individuals have more complications and the cumulative effect of increased complications in operative intervention leads to increased mortality [29].
Many patients can be treated non-operatively with advanced resuscitation, intensive care, and interventional radiology in the management of abdominal trauma. The patients usually receive close observation with fluid resuscitation or angioembolization [13, 14]. Safe modification of blunt abdominal trauma protocols with a focus on non-operative management in obese patients may avoid significant complications [30].

Postoperative care is important for trauma patients $[31,32]$. Obesity is a major risk factor for a number of chronic diseases, complications, and poor outcomes after surgery. Obese patients are difficult to liberate from ventilators and are predisposed to respiratory complications [33]. The treatment of ventilator-associated pneumonia or other infections is more complicated among the obese due to immune system dysregulation, decreased cell-mediated immune responses, and other reported possible mechanisms [34].

Total LOS and days in the ICU might be prolonged due to obesity [31,32]. The current study demonstrates that obesity is associated with a longer hospital and ICU LOS if the patients undergo laparotomies. This was not demonstrated in obese patients who did not receive laparotomies. A closer observation, aggressive resuscitation, and multidisciplinary treatment for associated comorbidities should be considered in the postoperative care of obese patients.

Our study has several limitations. The NTDB data are retrospective, not complete, and can be inaccurate. We restricted our records to patients with BMI $15-50 \mathrm{~kg} / \mathrm{m}^{2}$. 
Table 4 Multivariate logistic regression analysis for evaluation of independent risk factors for mortality in patients with laparotomy. (Patients without laparotomy were also analyzed as a control group.)

\begin{tabular}{|c|c|c|c|c|}
\hline \multirow[t]{2}{*}{ Variables } & \multirow[t]{2}{*}{$p$ value* } & \multirow[t]{2}{*}{ Odds of mortality } & \multicolumn{2}{|c|}{$95 \% \mathrm{CI}$} \\
\hline & & & Lower & Upper \\
\hline \multicolumn{5}{|l|}{ Laparotomy $(+)(N=10,987)$} \\
\hline Age & $<0.001$ & 1.034 & 1.027 & 1.042 \\
\hline Male & 0.028 & 1.433 & 1.041 & 1.973 \\
\hline $\mathrm{SBP}$ in $\mathrm{ED}(\mathrm{mmHg})$ & $<0.001$ & 0.987 & 0.984 & 0.990 \\
\hline Pulse in ED (/min) & 0.006 & 1.006 & 1.002 & 1.010 \\
\hline $\mathrm{RR}$ in $\mathrm{ED}(/ \mathrm{min})$ & 0.801 & 0.998 & 0.982 & 1.014 \\
\hline GCS in ED & $<0.001$ & 0.879 & 0.860 & 0.899 \\
\hline Penetrating & 0.512 & 1.098 & 0.830 & 1.453 \\
\hline Transportation time $(\mathrm{min})$ & 0.007 & 1.000 & 0.999 & 1.000 \\
\hline ED time (min) & 0.200 & 0.999 & 0.999 & 1.000 \\
\hline ISS & $<0.001$ & 1.087 & 1.070 & 1.103 \\
\hline Comorbidity & $<0.001$ & 0.572 & 0.441 & 0.740 \\
\hline Use of transfusion & $<0.001$ & 2.347 & 1.815 & 3.036 \\
\hline Obesity & 0.040 & 1.317 & 1.013 & 1.712 \\
\hline Constant & $<0.001$ & - & - & - \\
\hline \multicolumn{5}{|l|}{ Laparotomy $(-)(N=22,811)$} \\
\hline Age & $<0.001$ & 1.038 & 1.030 & 1.047 \\
\hline Male & 0.176 & 1.254 & 0.904 & 1.739 \\
\hline SBP in ED $(\mathrm{mmHg})$ & $<0.001$ & 0.991 & 0.987 & 0.996 \\
\hline Pulse in ED (/min) & 0.020 & 1.007 & 1.001 & 1.013 \\
\hline $\mathrm{RR}$ in $\mathrm{ED}(/ \mathrm{min})$ & 0.554 & 1.007 & 0.983 & 1.032 \\
\hline GCS in ED & $<0.001$ & 0.909 & 0.885 & 0.933 \\
\hline Penetrating & $<0.001$ & 2.872 & 1.780 & 4.632 \\
\hline Transportation time (min) & 0.839 & 1.000 & 1.000 & 1.000 \\
\hline ED time (min) & 0.973 & 1.000 & 1.000 & 1.000 \\
\hline ISS & $<0.001$ & 1.065 & 1.044 & 1.086 \\
\hline Comorbidity & 0.019 & 1.566 & 1.077 & 2.276 \\
\hline Use of transfusion & $<0.001$ & 3.848 & 2.782 & 5.322 \\
\hline Obesity & 0.831 & 1.037 & 0.746 & 1.441 \\
\hline Constant & $<0.001$ & - & - & - \\
\hline
\end{tabular}

*Multivariate logistic regression

$S B P$ systolic blood pressure, $E D$ emergency department, $R R$ respiratory rate, GCS Glasgow coma scale, ISS injury severity score, $C I$ confidence interval

Patients outside this range are rare [18]. Possible inaccuracies of procedure codes for abdominal operations also limit our conclusions. The aforementioned limitations notwithstanding the results depict important information about the role of obesity in the surgical outcomes of abdominal trauma patients. Further studies with prospective design and long-term follow-ups are needed. The effect of obesity to outcomes of abdominal trauma patients who received minimal invasive surgery also needs to be evaluated in future studies.

\section{Conclusion}

Obesity is associated with increased mortality and LOS in abdominal trauma patients who received laparotomies versus those who did not. A prudent approach to the 


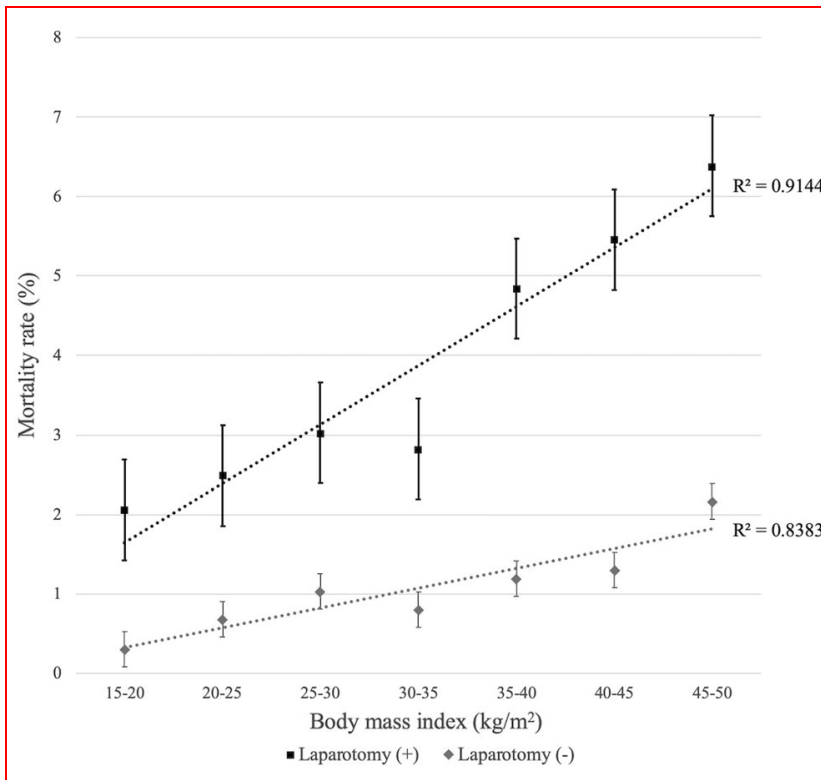

Fig. 2 Relationship between mortality and BMI in abdominal trauma patients who received laparotomy or not

decision to perform a laparotomy on obese patients is required.

Author contributions FB, C-YF, and FB were involved in the study conception and design. $\mathrm{C}-\mathrm{YF}$ was involved in acquisition of data. $\mathrm{FB}$, C-YF, FB, MB, FS, TM, MK, LCT, AD, VS, JM, and SP performed the analysis and interpretation of data. C-YF and RT drafted the manuscript. FB and FB performed the critical revision.

\section{Compliance with ethical standards}

Conflict of interest The authors have no commercial associations or sources of support from any grant, funding source, or commercial interest including pharmaceutical or device companies that might pose a conflict of interest.

\section{References}

1. Obesity: preventing and managing the global epidemic (2000) Report of a WHO consultation. World Health Organ Tech Rep Ser. vol 894, pp 1-253

2. Berghofer A, Pischon T, Reinhold T et al (2008) Obesity prevalence from a European perspective: a systematic review. BMC Public Health 8:200

3. Calle EE, Thun MJ, Petrelli JM et al (1999) Body-mass index and mortality in a prospective cohort of U.S. adults. N Engl J Med 341(15): 1097

4. Haslam DW, James WP (2005) Obesity. Lancet 366(9492):1197-1209

5. Cameron AJ, Welborn TA, Zimmet PZ et al (2003) Overweight and obesity in Australia the 1999-2000 Australian diabetes, obesity and lifestyle study. Med J Aust 178(9):427-432
6. Schwimmer JB, Burwinkle TM, Varni JW (2003) Health-related quality of life of severely obese children and adolescents. JAMA 289(14):1813-1819

7. Drenick EJ, Bale GS, Seltzer F et al (1980) Excessive mortality and causes of death in morbidly obese men. JAMA 243(5):443-445

8. Gendall KA, Raniga S, Kennedy R et al (2007) The impact of obesity on outcome after major colorectal surgery. Dis Colon Rectum 50(12):2223-2237

9. Scheidbach H, Benedix F, Hügel $\mathrm{O}$ et al (2008) Laparoscopic approach to colorectal procedures in the obese patient: risk factor or benefit? Obes Surg 18(1):66-70

10. Bège T, Lelong B, Francon D et al (2009) Impact of obesity on short-term results of laparoscopic rectal cancer resection. Surg Endosc 23(7):1460-1464

11. Ditillo M, Pandit V, Rhee P et al (2014) Morbid obesity predisposes trauma patients to worse outcomes: a National Trauma Data Bank analysis. J Trauma Acute Care Surg 76(1):176-179

12. Brahmbhatt TS, Hernon M, Siegert CJ et al (2017) Trauma and BMI mortality. Curr Obes Rep 6(2):211-216

13. Schwab CW (2001) Selection of nonoperative management candidates. World J Surg 25(11):1389-1392. https://doi.org/10. 1007/s00268-001-0137-x

14. Todd SR, Arthur M, Newgard C et al (2004) Hospital factors associated with splenectomy for splenic injury: a national perspective. J Trauma 57(5):1065-1071

15. Kurmann A, Vorburger SA, Candinas D et al (2011) Operation time and body mass index are significant risk factors for surgical site infection in laparoscopic sigmoid resection: a multicenter study. Surg Endosc 25(11):3531-3534

16. Lilienfeld DE, Vlahov D, Tennay JH et al (1988) Obesity and diabetes as risk factors for postoperative wound infections after cardiac surgery. Am J Infect Control 16(1):3-6

17. https://www.facs.org/quality-programs/trauma/ntdb. Accessed 20 July 2019

18. Berrington de Gonzalez A, Hartge P, Cerhan JR et al (2010) Body-mass index and mortality among 1.46 million white adults. N Engl J Med 363(9):2211-2219

19. Byrne JP, Mason SA, Gomez D et al (2016) Timing of pharmacologic venous thromboembolism prophylaxis in severe traumatic brain injury: a propensity-matched cohort study. J Am Coll Surg 223(4):621-631

20. https://www.who.int/topics/obesity/en/. Accessed 20 July 2019

21. https://www.facs.org/quality-programs/trauma/tqp/center-pro grams/ntdb/ntds/data-dictionary. Accessed 20 July 2019

22. Austin PC (2011) An introduction to propensity score methods for reducing the effects of confounding in observational studies. Multivar Behav Res 46(3):399-424

23. Austin PC (2009) Balance diagnostics for comparing the distribution of baseline covariates between treatment groups in propensity-score matched samples. Stat Med 28(25):3083-3107

24. R Core Team (2014) R: a language and environment for statistical computing. R Foundation for Statistical Computing, Vienna, Austria. http://www.R-project.org/. Accessed 20 July 2019

25. Neville AL, Brown CV, Weng J et al (2004) Obesity is an independent risk factor of mortality in severely injured blunt trauma patients. Arch Surg 139(9):983-987

26. GlobalSurg Collaborative (2016) Mortality of emergency abdominal surgery in high-, middle- and low-income countries. Br J Surg 103(8):971-988

27. GlobalSurg Collaborative (2016) Determinants of morbidity and mortality following emergency abdominal surgery in children in low-income and middle-income countries. BMJ Glob Health 1(4):e000091

28. Tengberg LT, Cihoric M, Foss NB et al (2017) Complications after emergency laparotomy beyond the immediate postoperative 
period-a retrospective, observational cohort study of 1139 patients. Anaesthesia 72(3):309-316

29. Healey MA, Shackford SR, Osler TM et al (2002) Complications in surgical patients. Arch Surg 137(5):611-617

30. Barry R, Modarresi M, Duran R et al (2019) The impact of obesity on outcomes in geriatric blunt trauma. Am Surg 85(2):188-195

31. Goulenok C, Monchi M, Chiche JD et al (2004) Influence of overweight on ICU mortality: a prospective study. Chest 125(4):1441-1445

32. El-Solh A, Sikka P, Bozkanat E et al (2001) Morbid obesity in the medical ICU. Chest 120(6):1989-1997
33. King P, Mortensen EM, Bollinger M et al (2013) Impact of obesity on outcomes for patients hospitalised with pneumonia. Eur Respir J 41(4):929-934

34. Tanaka S, Inoue S, Isoda F et al (1993) Impaired immunity in obesity: suppressed but reversible lymphocyte responsiveness. Int J Obes Relat Metab Disord 17(11):631-636

Publisher's Note Springer Nature remains neutral with regard to jurisdictional claims in published maps and institutional affiliations. 